\title{
THE GRONINGEN RADIOCARBON CALIBRATION PROGRAM
}

\author{
JOHANNES VAN DER PLICHT
}

Centre for Isotope Research, University of Groningen, Nijenborgh 4, 9747 AG Groningen, The Netherlands

\section{INTRODUCTION}

Variations in atmospheric ${ }^{14} \mathrm{C}$ content complicate the conversion of conventional ${ }^{14} \mathrm{C}$ ages $\mathrm{BP}$ (i.e., years before AD 1950) into real calendar ages (AD/BC) (de Vries 1958; Willis, Tauber \& Münnich 1960). These variations are indirectly observed in tree rings from European and North American wood. In recent decades, measurements made on dendrochronologically dated wood have resulted in the generally accepted Stuiver and Pearson calibration curves. These curves, together with other calibration data, were published in the first Radiocarbon Calibration Issue (Stuiver \& Kra 1986), and are extended in the present Calibration Issue (Stuiver, Long \& Kra 1993).

Irregularities in the calibration curve complicate the conversion of a $\mathrm{BP}^{14} \mathrm{C}$ age to a real calendar age (cal $\mathrm{AD} / \mathrm{BC}$ ). For example, the ${ }^{14} \mathrm{C}$ age can correspond to more than one real calendar date due to medium-term variations, or "wiggles" (Suess 1970). Consequently, transformation of the Gaussian probability distribution representing the measured ${ }^{14} \mathrm{C}$ age $(\mathrm{BP} \pm \sigma)$ is not straightforward. The real calendar age probability distribution is no longer Gaussian, unless the calibration curve happens to be a straight line in the time period considered (i.e., there is a linear relationship between cal $\mathrm{AD} / \mathrm{BC}$ and $\mathrm{BP}$ ). The calibrated age, then, cannot generally be stated as the most probable result, with an associated error bar.

Recently, several computer programs have been developed to calibrate ${ }^{14} \mathrm{C}$ dates. The most widely distributed programs are those from Seattle (Stuiver \& Reimer 1986) and Groningen (van der Plicht \& Mook 1987, 1989). The existing programs were compared at the 13th International Radiocarbon Conference in Dubrovnik (Aitchison et al. 1989). This comparison was necessary because of the different coding procedures used, mathematical complications caused by calibration curve wiggles, and different interpretations and/or presentations of results. The Groningen program is set up graphically; calibrated age ranges, based on confidence levels used in the Seattle program, have been incorporated, as agreed at the Conference.

The present upgraded version of the program, CAL15, is menu-driven. Previously distributed versions were CAL4 (van der Plicht \& Mook 1989) and CAL10. Knowledge of the programming language is not necessary to perform certain options. New features, such as wiggle matching, spline and smoothing (moving average) calculations are incorporated in the program. The mathematical justification for the calibration procedure used is described by Dehling and van der Plicht (1993).

\section{DESCRIPTION OF THE PROGRAM}

The present version of the program is written in Turbo Pascal, version 5.0 (Borland 1989). All options and subroutines are accessible through the main menu (Fig. 1). The program runs on $\mathrm{XT} / \mathrm{AT}$ or compatible computers with either CGA, Hercules, EGA or VGA graphics screens. The graphs can be sent to a color plotter (HP-compatible), laser printer (HP-compatible) or regular printer (Epson-compatible). The graph can also be stored on disk. The latter two options work only from screens in monochrome mode. 


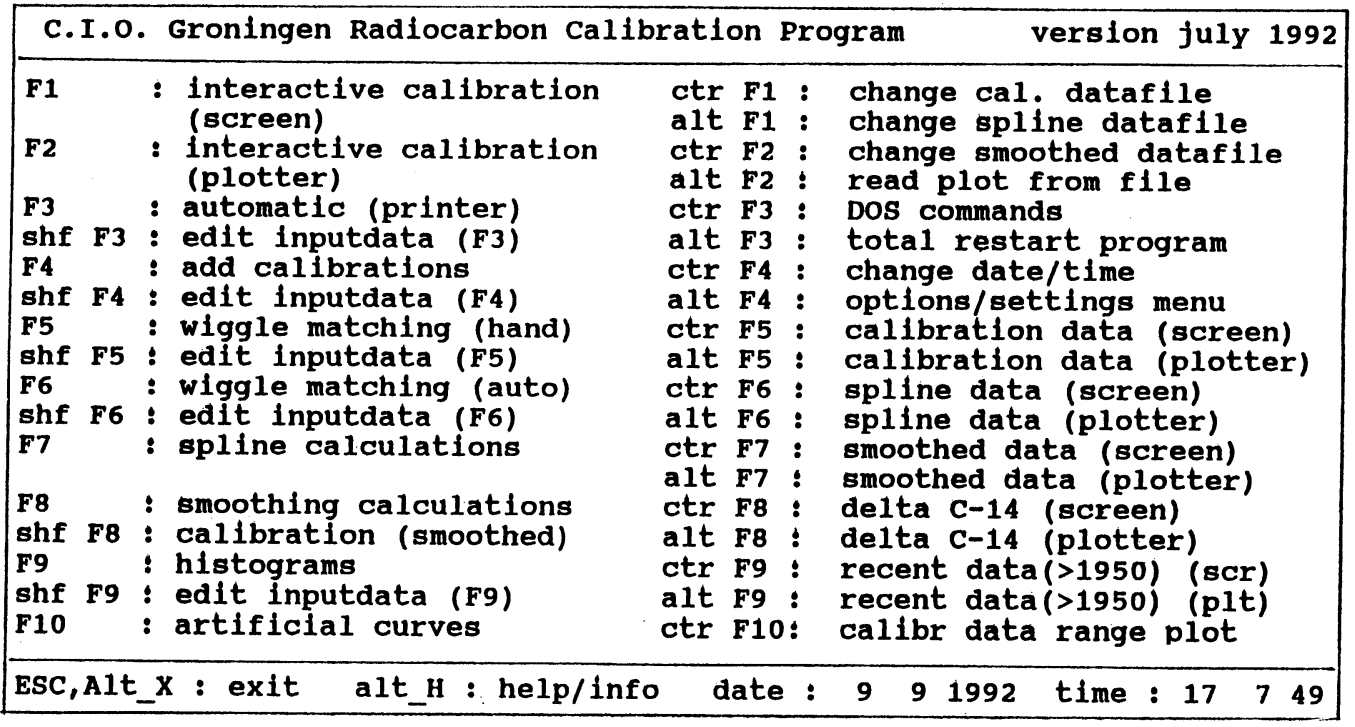

Fig. 1. The main menu of the Groningen Radiocarbon Calibration Program, CAL15

Most users will use just the interactive calibration option. One need make only three entries: the ${ }^{14} \mathrm{C}$ age to be calibrated (in BP), its error ( $\sigma \mathrm{BP}$ ) and an identification label (user-chosen text, such as, e.g., the GrN-number). The calibration procedure will start automatically, resulting in (usually) three graphs and analyzed output. The program uses default options, such as autoscaling the plots, the (recommended) calibration data from Stuiver and Pearson (1986) and the cubic spline function as calibration curve. Program functions are described below.

\section{The Calibration Procedure}

The ${ }^{14} \mathrm{C}$ age is the result of a statistical physical measurement, approaching a Gaussian probability distribution with the form

$$
\exp \left[-(y-\mathrm{BP})^{2} / 2 \sigma_{\mathrm{BP}}^{2}\right]
$$

The probability distribution along the $\mathrm{x}$-axis (the calendar axis) is not Gaussian; instead, it has the form

$$
\exp \left[-(f(x)-\mathrm{BP})^{2} / 2 \sigma_{\mathrm{BP}}^{2}\right]
$$

Here, $\mathrm{BP}$ is the ${ }^{14} \mathrm{C}$ age, $\sigma_{\mathrm{BP}}$ its error (standard deviation) and $y=f(x)$ the calibration function.

The computer program selects that part of the calibration curve corresponding to the ${ }^{14} \mathrm{C}$ age, $\mathrm{BP} \pm 3 \sigma_{\mathrm{BP}}$. In the corresponding area along the calendar axis, the function as defined above is calculated. The integration step size $(\mathrm{d} x)$ is usually taken as $4 \mathrm{yr}$ (corresponding to 5 steps for the $20-\mathrm{yr}$ intervals in the Stuiver and Pearson data set). In addition, the cumulative distribution: 


$$
P(x)=\int_{-\infty}^{x} \exp \left[-(f(x)-\mathrm{BP})^{2} / 2 \sigma_{\mathrm{BP}}^{2}\right] \mathrm{d} x
$$

is calculated, which is normalized by integrating to $x=\infty$. The calibration function, $y=f(x)$, is determined from the dendrochronologically measured calibration data points. The Groningen program uses a spline function or a smoothed curve calculated through these data points.

\section{Spline Function Calculation}

The spline function is calculated according to the procedure of Reinsch (1967). With this procedure, a smooth spline is calculated along a set of data points. The calculation is performed iteratively, such that

$$
\sum_{i}\left[\left(y\left(x_{i}\right)-y_{i}\right) / \sigma\left(y_{i}\right)\right]^{2} \leq S
$$

where $S$ is the "smoothing parameter". As discussed by Reinsch (1967), recommended values for $S$ depend on the magnitude of the standard deviations, $\sigma\left(y_{\mathrm{i}}\right)$. We have chosen $S=0$ (no smoothing), where the routine produces the natural cubic spline, i.e., it interpolates the data points. This also means that the error in the calibration data points is not taken into account.

The calculation results in four matrices, $a_{\mathrm{i}}, b_{\mathrm{i}}, c_{\mathrm{i}}$ and $d_{\mathrm{i}}$, which define the function

$$
f(x)=\left[\left(d_{i} \cdot h+c_{i}\right) \cdot h+b_{i}\right] \cdot h+a_{i}
$$

where $h=x-x_{\mathrm{i}}$, and $x_{\mathrm{i}} \leq x \leq x_{\mathrm{i}+1}$ are the calibration points. The matrices, $a_{\mathrm{i}}, b_{\mathrm{i}}, c_{\mathrm{i}}$ and $d_{\mathrm{i}}$ (for each calibration data set, and corresponding to the chosen smoothing parameter, $S$ ), are stored in a file, and called by the program CAL15. Once the spline function, $y=f(x)$, is calculated, the actual calibration can be performed, i.e, the transformation of the ${ }^{14} \mathrm{C}$ age (BP, $y$-axis) into the real calendar age (cal $\mathrm{AD} / \mathrm{BC}, \mathrm{x}$-axis) via the function, $y=f(x)$, using the formula described above.

\section{Smoothed Calibration Curve}

A smoothed calibration curve can be drawn through the calibration data points in various ways. First, the spline function can be calculated using a non-zero value for the smoothing parameter, $S$ (Reinsch 1967). The program also includes alternatively a code that calculates a smoothed curve through the data points with a Gaussian moving average. The curve may consist of several parts separated by a "breakpoint"; outliers may be rejected. The sigma (band width) of the Gaussian moving average is an input parameter, usually taken as three times the average distance between the data points.

\section{Output}

As stated, the user can easily perform "standard" calibrations by entering the ${ }^{14} \mathrm{C}$ age and its standard deviation BP. The program uses the Stuiver and Pearson (1986) data points as default calibration data, and a spline function with no smoothing (thus going through the data points) as default calibration function. The standard deviation of the calibration curve is ignored. Three graphs are produced by the program. The first graph shows the selected part of the calibration curve with 


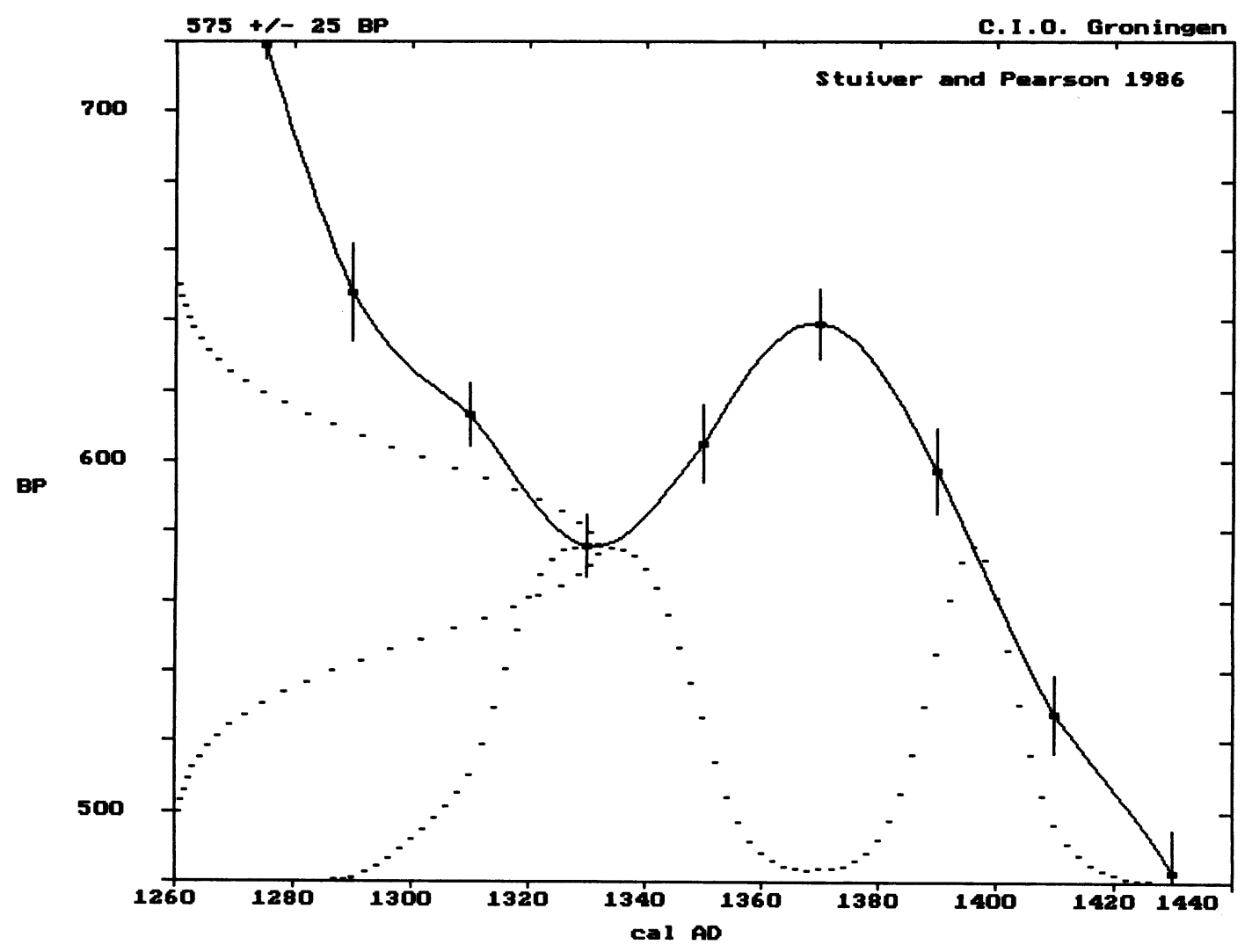

Fig. 2. Calibration of a ${ }^{14} \mathrm{C}$ age, $575 \pm 25$ BP

the calibration data points, the Gaussian probability distribution of the ${ }^{14} \mathrm{C}$ age along the $y$-axis, and the resulting calendar age probability distribution along the calendar axis. An example, calibrating $575 \pm 25 \mathrm{BP}$, is shown in Figure 2. Due to a "wiggle", the calibrated distribution has two peaks, centered around 1330 and $1395 \mathrm{cal} \mathrm{AD}$.

The second graph (Fig. 3) shows the cumulative probability, $P(x)$, as defined above. This plot corresponds to an earlier version of the program (van der Plicht, Mook \& Hasper 1990). In the example shown here, one may say that the peak around cal $\mathrm{AD} 1330$ has a probability of $65 \%$, and the one around $1395 \mathrm{cal} \mathrm{AD}, 35 \%$. The cumulative probability, $P(x)$, may be used to determine, e.g., the median, corresponding to $P(x)=0.5$. The use of "median" and "modus" ( $=$ the maximum of the calibrated distribution), however, is not recommended; see the discussion in van der Plicht and Mook (1989).

The third graph (Fig. 4) shows the calibrated calendar age probability distribution with lines indicating the $1 \sigma(68.3 \%)$ and $2 \sigma(95.4 \%)$ confidence intervals. The intercepts indicated by the vertical lines can be taken as calibrated ranges. In this example, the calibrated age ranges

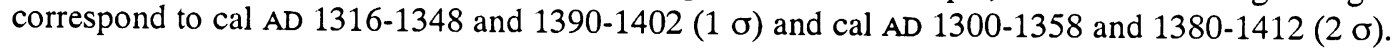

CAL15 produces output in terms of these calibrated age ranges $(1 \sigma$ and $2 \sigma)$. The graphs can be printed, plotted or saved to disk. 


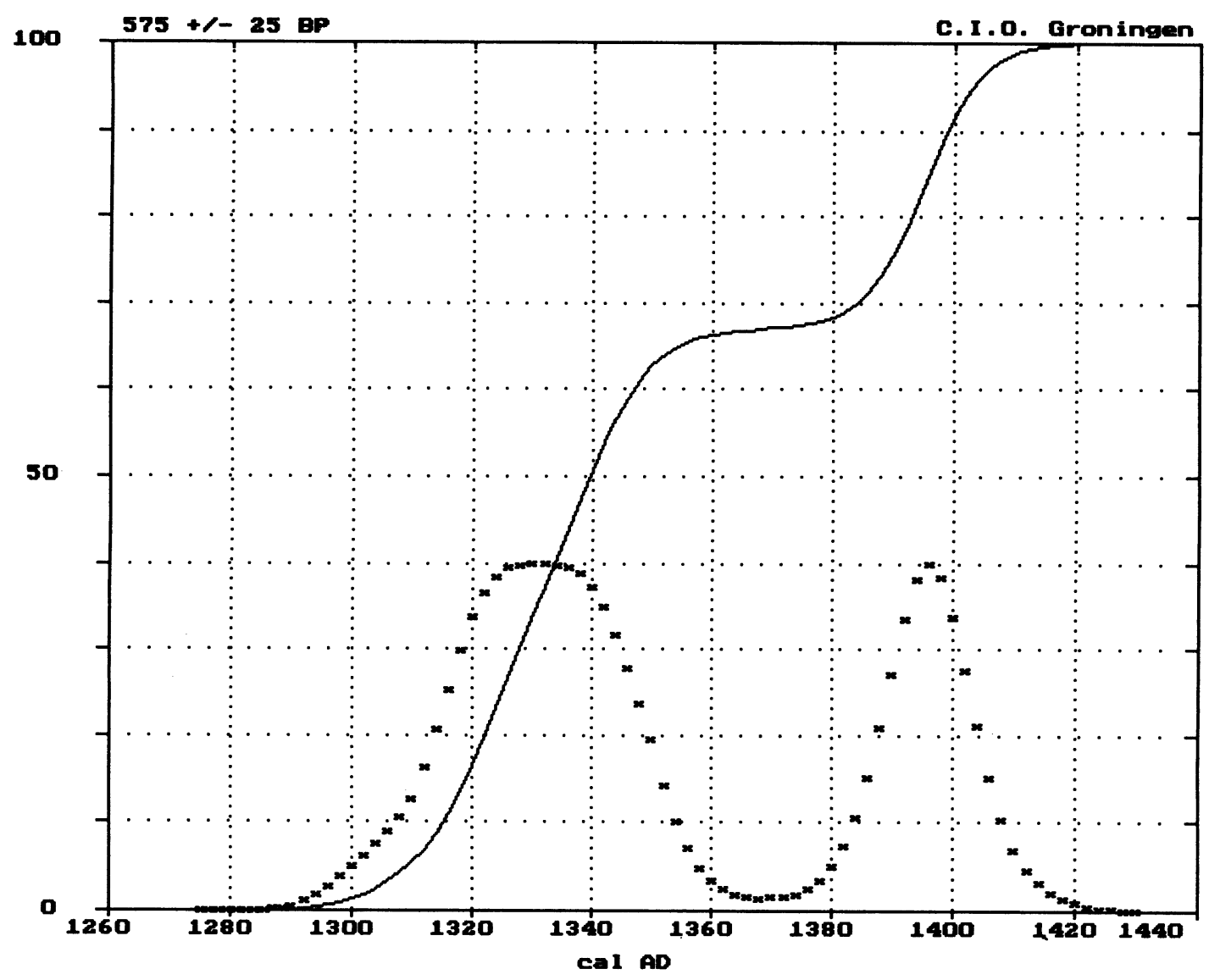

Fig. 3. Cumulative probability distribution for calibrating $575 \pm 25$ BP

\section{SPECIAL OPTIONS}

\section{Calibration of Multiple Dates}

A series of ${ }^{14} \mathrm{C}$ dates can be analyzed by the program in several ways, depending on their relation. First, non-related dates read from an input file can be calibrated automatically, without user interaction. The calibrated date ranges $(1 \sigma)$ can be plotted on an additional graph for this option. Second, the calibrated probability distributions for a series of related dates can be summed together. The results for the individual calibrations are normalized so that the area, $f(x) \mathrm{d} x=1$. Of the total summed function, $y_{\text {tot }}(x)$, the probability distribution is calculated, and analyzed for $1 \sigma$ or $2 \sigma$ calibrated age ranges as discussed above.

\section{Non-Dendrochronological Calibration Data}

Not all calibration data are obtained from dendrochronologically-dated wood. For instance, Stuiver et al. (1991) constructed a calibration data set to 30,000 BP, using high-precision U/Th dates from corals and comparing these data with ${ }^{14} \mathrm{C}$ results. From this data set, CAL15 can construct a calibration curve by calculating a smoothed curve through the data points. 


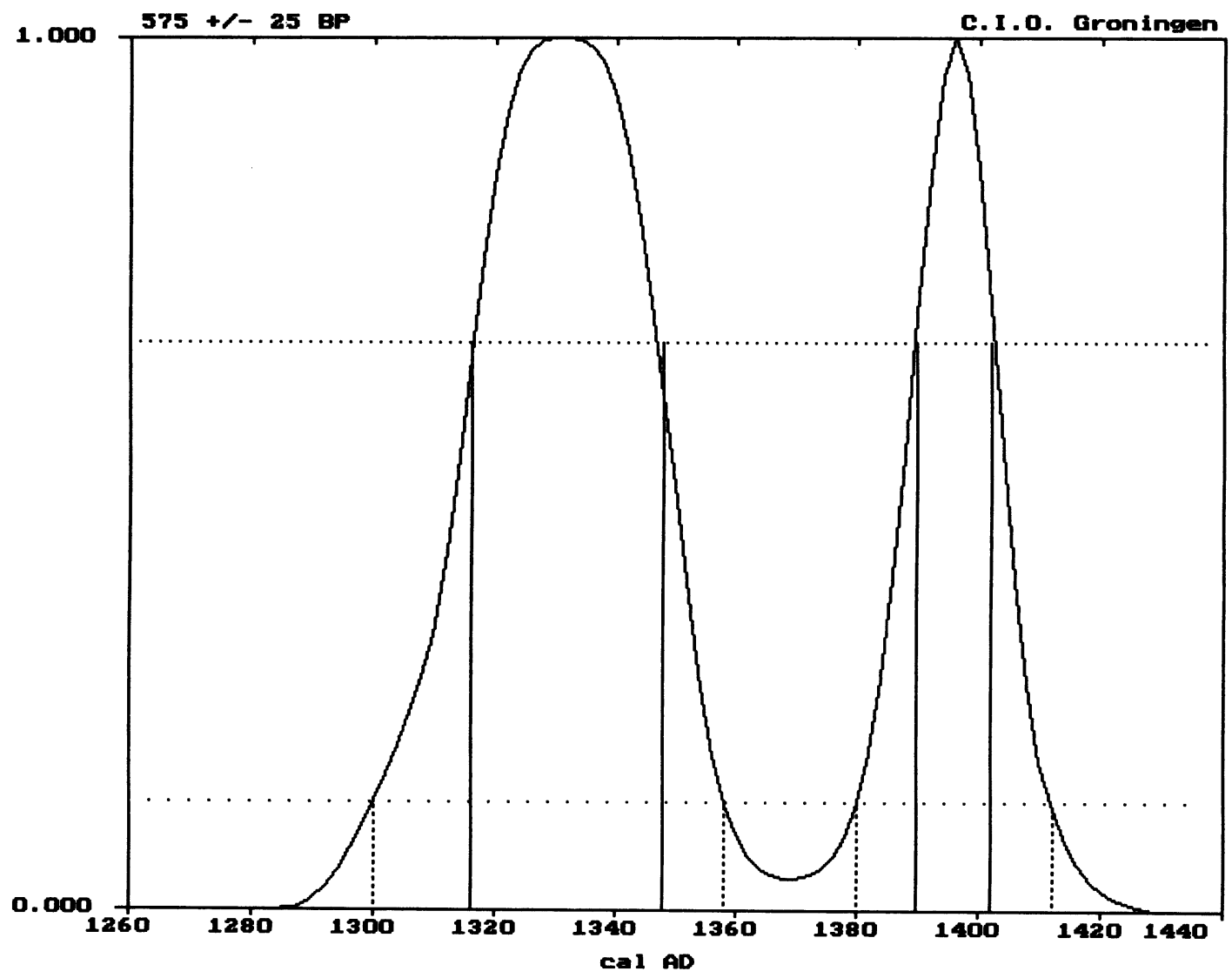

Fig. 4. Calendar axis probability distribution for $575 \pm 25 \mathrm{BP}$, with levels corresponding to $1 \sigma$ and $2 \sigma$ confidence

\section{Wiggle Matching}

CAL15 has two wiggle matching modes: tree-ring wiggle matching (i.e., data that are fixed along the calendar axis), and wiggle matching for data that are not necessarily fixed along the calendar axis. The latter can be applied where there is variable growth (van Geel \& Mook 1989). In the present version of the program, wiggle matching can only be estimated, i.e., the best "fit" of the data to the relevant part of the calibration curve is determined visually; either a mouse or arrow keys can be used. An automatic wiggle-matching procedure will be included in the next release of the program. Wiggle-matching calculations are complex, especially for peat layers with variable growth rates.

\section{SUMMARY AND CONCLUSION}

We developed a PC-based computer program, CAL15, for automatic calibration of ${ }^{14} \mathrm{C}$ ages, written in Turbo Pascal (version 5.0). The program uses a spline function generated through the calibration data points, as published in the Radiocarbon Calibration Issues (Stuiver \& Kra 1986; Stuiver, Long and $\mathrm{Kra}$ 1993). The Gaussian probability distribution of the ${ }^{14} \mathrm{C}$ age is taken at the $3 \sigma$ level. The program automatically selects part of the calibration curve and calculates the calibrated probability distribution along the calendar axis; one only enters the date to be calibrated (in BP), the associated 
error ( $\sigma \mathrm{BP})$ and a text label, either interactively or through an input file.

The calibrated results are produced mainly in graphical form. The calibrated dates are presented as $1 \sigma(68.3 \%)$ or $2 \sigma(95.4 \%)$ confidence levels. As a default, the recommended calibration data set from Stuiver and Pearson (1986) is used. The default calibration curve is an unsmoothed cubic spline function (Reinsch, 1967) through the calibration data points. Some smoothing, however, may be more realistic, for instance, when the time width of the sample is taken into account (Mook 1983). In CAL15, the user can easily calculate a spline function; the smoothing parameter, $S$, is entered. The results of the calculation (i.e., the matrices $a_{\mathrm{i}} \ldots d_{\mathrm{i}}$ ) are stored in a data file, which can be loaded into the main program to perform the calibration with the newly calculated spline function. At present, there is no convention concerning the shape of the calibration curve, calculated through the calibration data points. See also the discussion by Talma and Vogel (1993).

CAL15 also features powerful graphics to display the calibration data sets, calibration functions calculated by spline and smoothing techniques, test curves and $\Delta^{14} \mathrm{C}$ values (see the main menu, Fig. 1). The graphs can be printed or plotted, depending on the selection from the menu. CAL15 runs most efficiently from an AT with VGA/color screen and hard disk. Program size is $180 \mathrm{~kb}$. It also works on an XT or without a hard disk, albeit considerably slower. Saving graphs to disk is not practical without a hard disk, since abundant disk space is required (up to $45 \mathrm{~kb}$ for VGA screens). The program and necessary data files can be obtained from the Groningen Laboratory.

\section{REFERENCES}

Aitchison T. C., Leese, M., Michczynska, D. J., Mook, W. G., Otlet, R. L., Ottaway, B. S., Pazdur, M. F., van der Plicht, J., Reimer, P. J., Robinson, S. W., Scott, E. M., Stuiver M. and Weninger, B. 1989 A comparison of methods used for the calibration of radiocarbon dates. In Long, A., Kra., R.S., eds., Proceedings of the 13th International ${ }^{14} \mathrm{C}$ Conference. Radiocarbon 31(3): 846-862.

Borland 1989 Turbo Pascal. Scotts Valley, California 95066 USA.

de Vries, H. 1958 Variation in concentration of radiocarbon with time and location on earth. Proceedings Koninklijke Nederlandse Akademie van Wetenschappen 61(B): 1-9.

Dehling, H. and van der Plicht, J. 1993 Statistical problems in calibrating radiocarbon dates. Radiocarbon, this issue.

Mook, W. G. $1983{ }^{14} \mathrm{C}$ calibration curves depending on sample time width. In Mook, W. G. and Waterbolk, H. T., eds., Proceedings of the International Symposium on ${ }^{14} \mathrm{C}$ and Archaeology. PACT 8: 517-525.

Reinsch, C. H. 1967 Smoothing by spline functions. Numerische Mathematik 10: 177-183.

Stuiver, M. and Kra, R. S., eds., 1986 Calibration Issue. Proceedings of the 12th International ${ }^{14} \mathrm{C}$ Conference. Radiocarbon 28(2B): 805-1030.

Stuiver, M. and Reimer, P. J. 1986 A computer program for radiocarbon age calculation. In Stuiver, $M$. and Kra, R.S., eds., Proceedings of the 12th International ${ }^{14} \mathrm{C}$ Conference. Radiocarbon 28(2B): 1022-1030.

Stuiver, M., Braziunas F., Becker, B. and Kromer, B. 1991 Climatic, solar, oceanic and geomagnetic influences on Late-Glacial and Holocene atmospheric ${ }^{14} \mathrm{C} /{ }^{12} \mathrm{C}$ change. Quaternary Research 35: 1-24.

Stuiver, M., Long A. and Kra, R. S., eds., 1993 Calibration Issue 1993. Radiocarbon, this issue.

Suess, H. E. 1970 The three causes of secular C14 fluctuations, their amplitudes and time constants. In Olsson, I.U. ed., Radiocarbon Variations and Absolute Chronology. Proceedings of the 12th Nobel Symposium. Stockholm, Almqvist \& Wiksell, p. 595-605.

Talma, A. S. and Vogel, J. C. 1993 A simplified approach to calibrating ${ }^{14} \mathrm{C}$ dates. Radiocarbon $35(3)$ : in press.

van Geel, B. and Mook, W. G. 1989 High-resolution ${ }^{14} \mathrm{C}$ dating of organic deposits using natural atmospheric ${ }^{14} \mathrm{C}$ variations. Radiocarbon 31(2): 151-155.

van der Plicht, J. and Mook, W. G. 1987 Automatic radiocarbon calibration: Illustrative examples. Palaeohistoria 29: 173-182.

1989 Calibration of radiocarbon ages by computer. In Long, A. and Kra, R. S., eds., Proceedings of the 13th International ${ }^{14} \mathrm{C}$ Conference. Radiocarbon 31(3): 805-816.

van der Plicht, J., Mook, W. G. and Hasper, H. 1990 Automatic calibration of Radiocarbon Ages. In Mook W. G. and Waterbolk, H. T., eds., Proceedings of the Second International Symposium on ${ }^{14} \mathrm{C}$ and Archaeology. PACT 29: 81-94.

Willis, E. H., Tauber, H. and Münnich, K. O. 1960 Variations in the atmospheric radiocarbon concentration over the past 1300 years. American Journal of Science Radiocarbon Supplement 2: 1-4. 